\title{
BURDEN OF CAREGIVING AND LIFE SATISFACTION AMONG THE CAREGIVERS OF CHILDREN WITH AUTISM SPECTRUM DISORDER
}

\section{Sawera Khan', Iffat Batool', Nasreen Akhtar ${ }^{1 \otimes}$}

\begin{abstract}
OBJECTIVE: To examine the predictive relationship between burden of caregiving and life satisfaction among the caregivers of children with Autism Spectrum Disorder (ASD) from different cities of Panjab, Pakistan.

METHODS: This correlational study was conducted from January - June 2019, on 7I caregivers of ASD patients from different cities of Punjab province, registered with different autism treatment centers, Lahore- Pakistan. Informed consent was taken from caregivers, selected through purposive sampling technique. Caregiver burden scale by Zarit Burden Scale was used to measure family burden while Satisfaction with Life Scale by Diener ED, was used to measure life satisfaction among the care givers.
\end{abstract}

RESULTS: Out of 71 caregivers of children with ASD, 55 (77.5\%) were females and 16 (22.5\%) were males. Caregivers ranged in age from 20-55 years and majority $(n=33 / 71: 46.5 \%)$ were from $31-40$ years age group. Forty-seven (66.2\%) caregivers belonged to joint family. Majority (36/7I, 50.7\%) of caregivers had I-3 children and 24 (33.8\%) caregivers had 4-6 children. Zarit Burden Scale has a high reliability $(\alpha=.84)$ and Life Satisfaction Scale has satisfactory reliability $(\alpha=.74)$ for current sample. The findings of the study revealed significant negative relationship between burden of caregiving and life satisfaction $(r=-0.33, p<0.05)$. Regression analysis predicted family burden to be negatively associated with life satisfaction $\alpha=-0.17, p<0.05$. The results reported significant effect of levels of burden on life satisfaction $\left(R^{2}=0.1 \mathrm{I}\right.$, $\mathrm{p}<0.05)$.

CONCLUSION: Caregiver burden negatively predicts the life satisfaction indicating that caregivers who experience more burden are less satisfied with life.

KEY WORDS: Burden of caregiving (Non-MeSH); Life satisfaction (Non$\mathrm{MeSH}$ ); Zarit Burden Scale (Non-MeSH); Satisfaction with Life Scale (Non$\mathrm{MeSH})$; Autism Spectrum Disorder (MeSH).

THIS ARTICLE MAY BE CITED AS: Khan S, Batool I, Akhtar N. Burden of caregiving and life satisfaction among the caregivers of children with autism spectrum disorder. Khyber Med Univ J 2020;13(2):71-5. https://doi.org/l0.35845/kmuj.202I.1986I

\section{INTRODUCTION}

$\Delta$ utistic children face difficulties in communication, poor in selfhelp skills, have limited interests and strong adherence to routine tasks. The caregivers perceive many difficulties and pressures while taking care of autistic children and these adversities include physical strain, psychological distress, emotional exhaustion, and socioeconomic turmoil. Hence, they become greatly dependent upon the people who are responsible for their care and support and this feeling of being constantly responsible for someone with disability becomes a tiresome process. These difficulties aggravate when the demands of caregiving outweigh the available financial resources.' Financial strain involved in the upbringing of children with autism is far more as compared to the average / typical / normal children. ${ }^{2}$ Moreover, parents had to take leave from their works or have limited professional choices owing to their duties for autistic children. More often such problems end up into mental, social and physical hazards for the parents.
I: Department of Psychology, Government College University Lahore, Lahore, Pakistan.

Contact \# +92-347-4446362

Email凶: nasreenakhtar5।@gmail.com

Date Submitted: November 05, 2019

Date Revised: June 01,202I

Date Accepted: June 05, 202।

Families having children with developmental disabilities experience more negative psychological outcomes than families with average / typical /normal children. ${ }^{4}$ Families experience additional financial burdens, more restrictions in social activities, and heightened parental stress. As a group, parents of children with autism seem to experience even more stress than parents of children with other disabilities. ${ }^{5}$ A quasi-experimental study investigated the worth of life and individual load on caretakers ( 86 female careginvers) of ASD children and found that the care providers of autistic children reported greater strain and deficit in life as compared to experimental group (36 caregivers).

Another important aspect is the life satisfaction of caregivers of autistic children. Life satisfaction is "an overall assessment of feelings and attitudes about one's life at a particular point in time ranging from negative to positive". It is one of three major indicators of well-being: life satisfaction, positive affect and negative affect. ${ }^{7}$ Satisfaction with life is also defined as "desire to change one's life; satisfaction with past; satisfaction with future; and significant other's views of one's life". ${ }^{8}$ Life satisfaction is a universal concept which indicates a positive approach towards the life in general. ${ }^{9}$ Healthier and happier persons focus less on adversities the life brings to them. Such people are not only friendly but they also play an important role in promoting a happier and healthier life which in turn raises the levels of satisfaction among the individuals. " Life satisfaction effects the individual in two ways: (a) Microsocial life domains, i.e., living conditions, 
TABLE I: DEMOGRAPHIC CHARACTERISTICS OF CASRE GIVERS ( $\mathbf{N}=7$ I)

\begin{tabular}{|l|l|c|c|}
\hline \multicolumn{2}{|c|}{ Parameters } & Frequency & Percentage \\
\hline \multirow{3}{*}{ Gender } & Female & 55 & 77.5 \\
\cline { 2 - 4 } & Male & 16 & 22.5 \\
\hline \multirow{4}{*}{ Age (years) } & $20-30$ & 19 & 26.8 \\
\cline { 2 - 4 } & $31-40$ & 33 & 46.5 \\
\cline { 2 - 4 } & $41-50$ & 15 & 21.1 \\
\cline { 2 - 4 } & $5 \mathrm{I}-55$ & 4 & 5.6 \\
\hline \multirow{3}{*}{ Family system } & Joint & 47 & 66.2 \\
\cline { 2 - 4 } & Nuclear & 24 & 33.8 \\
\hline \multirow{3}{*}{ Marital status economic status } & Low & 23 & 32.4 \\
\cline { 2 - 4 } & Middle & 27 & 38.0 \\
\cline { 2 - 4 } & High & 21 & 29.6 \\
\hline \multirow{3}{*}{ No of children } & Single (key relatives) & 11 & 15.5 \\
\cline { 2 - 4 } & Married & 54 & 76.1 \\
\cline { 2 - 4 } & Divorced & 6 & 8.5 \\
\hline & Nil & 11 & 15.5 \\
\cline { 2 - 4 } & I-3 & 36 & 50.7 \\
\cline { 2 - 4 } & $4-6$ & 24 & 33.8 \\
\hline
\end{tabular}

including features such as work-related conditions, subjective health conditions, marital status, financial household status. (b) Macro-social life domains, i.e., Societal conditions, including aspects such as government performance, political democracy, welfare growth and economic equality.

Various determinants of life satisfaction were observed among the caregivers of children with developmental disabilities in South Korea. The objective was to explore those factors that are linked with life satisfaction in the caregivers through the data taken from 390 caregivers. It was reported that age of both the child and the care provider have negative impact on the life satisfaction of the caregivers of children with autism spectrum disorder (ASD) . Whereas, levels of child's disability and the socioeconomic status of the family was positively correlated with caregivers life satisfaction. At the same time life satisfaction decreases with increased strain related to caregiving

TABLE II: DESCRIPTIVE STATISTICS AND ALPHA COEFFICIENTS OF CAREGIVER BURDEN SCALE AND LIFE SATISFACTION SCALE ( $\mathbf{N}=7$ I)

\begin{tabular}{|l|c|c|c|c|}
\hline Scale & $\mathbf{k}$ & $\mathbf{M}$ & SD & $\alpha^{\#}$ \\
\hline Zarit Burden Scale & 22 & $4 I .8 \mathrm{I}$ & 12.734 & .84 \\
\hline Life Satisfaction Scale & 5 & 22.50 & $6.3 \mathrm{I}$ & .74 \\
\hline
\end{tabular}

\#: Cronbach's alpha

and finances but duration of caregiving didn't show any particular effect upon life satisfaction. ${ }^{12}$

ASD is a life long disability and caregivers of these children equip themselves with strategies to face the related pressures accordingly. The rationale behind the study was to predict how burden of caregiving influence the life satisfaction of parents/ caregivers who are going through the lifelong struggle with children suffering from ASD. The objective of the study was to investigate the relationship between burden of caregiving and life satisfaction among the caregivers of children with ASD and to find out the predictive influence of caregivers' burden on their life satisfaction among the caregivers of children with ASD.

\section{METHODS}

The correlational survey research was conducted from January-June 2019 on caregivers of ASD patients who were registered with different autism treatment centres, Lahore, Pakistan. Study was approved by the depart-mental board of studies and university's board of ethics review committee of Government College University Lahore, Lahore, Pakistan with certificate number GCU/IIB/787.

Inclusion criteria for participants was caregivers, having a child diagnosed with ASD, with education level of graduation. Exclusion criteria for this study was caregivers of children with developmental (learning, intellect) delays and disorders.

Seventy one caregivers from different cities of Punjab of children with ASD were selected through purposive sampling technique. More often, the sample size for clinical research is always smaller than general community sample. Out of 7I caregivers, 55 $(77.5 \%)$ were females and $16(22.5 \%)$ were males. The number of male participants was smaller because Pakistani males reported less involvement with the child in the care giving process." Informed consent was taken from all caregivers of ASD before enrolling in the study.

This study was specific to the area of clinical psychology. Hence findings are applicable only to caregivers of ASD. For the current study two questionnaires used were caregiver burden scales and satisfaction with life scale.

Zarit Burden scale (ZBI) was developed in 1980 by Zarit. It is the most widely used instrument for assessing the burden experienced by the caregivers. ${ }^{12}$ It is a 29-item scale with 5-point Likert rating ranging from 0 to 4 . It consists of five subscales including, Burden in the relationship (I, 8, II, I4, 18, 20), Emotional well-being $(2,4,5,9,10,21$, $22)$, Social and family life $(3,6,12,13)$, Finances (15), and Loss of control over one's life $(7,16,17,19)$. It has a good internal reliability (Cronbach alpha coefficient of 0.92). ${ }^{13}$ The internal consistency of the scale for the present study was ( $\alpha=0.88)$.

Satisfaction with Life Scale (SWLS) It is a 5 -item scale designed to measure global cognitive judgments of one's life satisfaction. ${ }^{14}$ Participants indicate how much they agree or disagree with each 
TABLE III: INTER-CORRELATION AMONG STUDY VARIABLES $(\mathbf{N}=7$ I $)$

\begin{tabular}{|l|l|c|c|c|c|c|c|c|}
\hline S.No & Source & $\mathbf{I}$ & $\mathbf{2}$ & $\mathbf{3}$ & $\mathbf{4}$ & $\mathbf{5}$ & $\mathbf{6}$ & $\mathbf{7}$ \\
\hline I. & Burden caregiver & -- & $-0.33^{*}$ & $0.75 * *$ & $0.90^{* *}$ & $0.80^{* *}$ & $0.52^{* *}$ & $0.78^{* *}$ \\
\hline 2. & Life satisfaction & & -- & -0.20 & $-0.3 I^{*}$ & -0.17 & -0.13 & $-0.36^{*}$ \\
\hline 3. & Burden in relationship & & & -- & $0.61^{* *}$ & $0.58^{* *}$ & $0.23 *$ & $0.44^{* *}$ \\
\hline 4. & Emotional well-being & & & & -- & $0.64 * *$ & $0.50^{* *}$ & $0.60 * *$ \\
\hline 5. & Social and family life & & & & & -- & $0.23 *$ & $0.5 I^{* *}$ \\
\hline 6. & Finance & & & & & & $0.38^{*}$ \\
\hline 7. & Loss of control & & & & & & -- \\
\hline
\end{tabular}

of the 5 items using a 7-point scale that ranges from 7 strongly agree to I strongly disagree. It has a good internal reliability (Cronbach alpha coefficient ranges from $(\alpha=0.84$ to 0.96$)$. The internal consistency of the scale for the present study was $(\alpha=0.74)$. In the present study, research ethics were maintained throughout the research. First of all, permission for using the scales was taken from the respective authors through email correspondence. Permission was obtained from the respective heads of the institutes of children with ASD. Verbal consent of the participants was also taken and it was clarified that their participation in the study was voluntary and that information to be kept confidential and it was assured that their participation will not cause any harm or damage to caregivers and children with ASD them.

Data of current study was analyzed by using software SPSS 2I. Correlational analysis was done to see the relationship between life satisfaction and family burden among the caregivers. Analysis of variance was conducted to see the difference in life satisfaction with different levels of burden among the caregivers as well as the differences between socioeconomic status, gender and family system with family burden and life satisfaction were explored.
Regression analysis was run to predict the role of family burden over the life satisfaction among the caregivers.

\section{RESULTS}

Out of 7I caregivers of children with ASD, 55 (77.5\%) were females and 16 $(22.5 \%)$ were males. Caregivers were ranging in age from 20 to 55 years. Most of the caregivers $(n=33 ; 46.5 \%)$ were from age group 31-40 year and 19 (26.8\%) were from $20-30$ years of age. Forty seven (66.2\%) caregivers belonged to joint family. Majority (36/7I, 50.7\%) of caregivers had I-3 children (Table I).

Table II indicates that Zarit Burden Scale has a high reliability $(\alpha=.84)$ and life satisfaction scale has satisfactory reliability $(\alpha=.74)$ for current sample. It means that questionnaires used in the current sample were reliable.

Table III demonstrated that there is a negative relationship among caregiver burden and life satisfaction $(r=-.33)$. Moreover, caregivers who reported higher burden were found higher in terms of burden in relationship $(r=.75)$ and lower in terms of emotional well-being $(r=.90)$, social and family life $(r=.80)$, loss of control $(r=.78)$ and finance $(r=.52)$.

Table IV indicate that high burden of

TABLE IV: BURDEN OF CAREGIVING AS PREDICTOR OF LIFE SATISFACTION $(\mathbf{N}=7$ I $)$

\begin{tabular}{|l|c|}
\hline Predictors & B \\
\hline Constant & 29.91 \\
\hline Burden of Caregiver & $-0.17^{*}$ \\
\hline$R$ & 0.33 \\
\hline$R^{2}$ & 0.11 \\
\hline F & 8.60 \\
\hline
\end{tabular}

care predicts poor life satisfaction among caregivers $(\alpha=-0.17, p<.05)$. $\mathrm{R}^{2}=0.1 \mathrm{l}$ shows that burden of care explains I I \% variance in life satisfaction among caregivers.

\section{DISCUSSION}

The present study was designed to examine the relationship of burden of caregiving and life satisfaction among the caregivers of children with ASD. The findings of the study revealed significant negative relationship between burden of caregiving and life satisfaction. Regression analysis predicted family burden to be negatively associated with life satisfaction.

First hypothesis stated that there would be a significant relationship in family burden and life satisfaction among the caregivers of children with ASD. The results of the study also supported the first hypothesis and showed negative correlation between burden and life satisfaction among the caregivers of children with ASD. The caregivers who experienced more burden of care were poorly satisfied with their lives. Same results were reported in a previous correlational study on life satisfaction, caregiver burden and caregiver selfefficacy. ${ }^{16}$ Results indicated that caregivers' burden decreased their life satisfaction. Moreover, caregivers who reported higher burden were found higher in terms of burden in relationship $(r=.75)$ and lower in terms of emotional well-being $(r=.90)$, social and family life $(r=.80)$, loss of control $(r=.78)$ and finance $(r=.52)$.

Second hypothesis states that family burden is likely to predict life satisfaction. In the second hypothesis, results of the study proposed that burden of caregiving will negatively 
predict life satisfaction. The present study also reported that burden is negatively predicting the life satisfaction among caregivers so they experience burden more and are not satisfied with their lives. No previous literature was found in this concern showing direct prediction between the study variables but a related research reported sociodemographic characteristics and carerelated stressors among caregivers of children with developmental disabilities (CDD) predict their life satisfaction. ${ }^{12}$ Similar results were reported in a research conducted on mentally disabled children and risk factors of the family. Results indicated that level of burden differ significantly in life satisfaction of the individuals. ${ }^{17}$ Looking beyond families of individuals with ASD, several studies of caregivers of individuals with intellectual disabilities also reported an association between caregiver burden and life satisfaction. ${ }^{18}$

In present study, the phenomena of family burden and life satisfaction among the caregivers of autistic children was explored quantitatively. In future, qualitative study needs to be carried out to explore the experiences of caregivers specifically mothers about burden of caregiving and life satisfaction. Due to shortage of time, the sample size couldn't be increased and was restricted to one city only which has reduced the opportunity for the generalization of the study. The results can be generalized in future by increasing sample size and collecting data from different major cities of Pakistan. Moreover, the present study included educated caregivers as the mode of data collection was questionnaire. In future studies, data can be collected by conducting structured interviews. The present study focused only on two variables which were family burden and life satisfaction. Future researchers can study the role of optimism and personality related variables as correlates of burden of caregiver.

\section{CONCLUSION}

Caregivers especially mothers of children with autism spectrum disorder experienced higher burden of care and were less satisfied with their lives. Caregiver burden was a significant predictor of poor life satisfaction among caregivers.

\section{ACKNOWLEDGMENTS}

The authors are very thankful to hospital administration and caregivers of patients for providing data to complete this research work.

\section{REFERENCES}

I: Brannan AM, Heflinger CA, Bickman L. The Caregiver Strain Questionnaire: Measuring the impact on the family of living with a child with serious emotional disturbance. J Emot Behav Disord 1997;5(4):212-22. https://doi.org/ | 0.1 | 77// 06342669700500404 .

2: Peters-Scheffer N, Didden R, Korzilius H, Matson J. Cost comparison of early intensive behavioral intervention and treatment as usual for children with autism spectrum disorder in the Netherlands. Res Dev Disabil 2012;33(6):I763-72. https://doi.org//0.1016/ j.ridd.20I2.04.006.

3: Bromley J, Hare DJ, Davison K, Emerson E. Mothers supporting children with autistic spectrum disorders: Social support, mental health status and satisfaction with services. Autism 2004;8(4):409-23. https://doi.org/10.1 I77//36236/30 4047224

4: Hauser-Cram P, Warfield ME, Shonkoff JP, Krauss MW. II. The development of children with disabilities and the adaptation of their parents: Theoretical perspectives and empirical evidence. Monogr Soc Res Child Dev 200I;66(3):6-2I. https://doi.org/10.1III/I5405834.00152

5: Dumas JE, Wolf LC, Fisman SN, Culligan A. Parenting stress, child behavior problems, and dysphoria in parents of children with autism, Down syndrome, behavior disorders, and normal development. Exceptionality |99।;2(2):97-I।0. https://doi.org/10.1080/09362839। 09524770.

6: Ezzat O, Bayoumi M, Samarkandi OA. Quality of life and subjective burden on family caregiver of children with autism. Am J Nurs 2017;6(I):33-9. https://doi.org/ 10.1 I648/j.ajns.20I7060I.15.

7: Diener E. Subjective well-being. Psychol Bull 1984;95(3):542. https://doi.org/10.1 I77/014616728 5111008

8: Diener E, Suh EM, Lucas RE, Smith HL. Subjective well-being: Three decades of progress. Psychol Bull 1999; | 25(2):276.

9: Haybron D. Life satisfaction, ethical reflection, and the science of happiness. J Happiness Stud 2007;8(I):99-I38.

10: Lopez S, McWhirter A, Rosencrans M, Giuliani NR, Mclntyre LL. Father involvement with children with developmental delays. Glob Educ Rev 2019;6(I):40-62.

I I: Seligman ME, Pawelski JO. Positive Psychology: FAQS. Psychol Inq 2003; I4(2): I59-63.

12: Cho S, Kahng SK. Predictors of life satisfaction among Caregivers of children with developmental disabilities in South Korea. Asian Soc Sci 20I5; I I(2): I54. https://doi.org/ 10.5539/ass.vI In2pI54.

13: Zarit S, Reever K, Bach-Peterson J. Relatives of impaired elderly: Correlates of feelings of burden. Gerontologis 1980;20(6): 649-55. https://doi.org/10.1093/geront/ 20.6.649.

14: Yap P. Validity and reliability of the Zarit Burden Interview in assessing caregiving burden. Ann Acad Med Singap 2010;39:758-63.

I5: Diener ED, Emmons RA, Larsen RJ, Griffin S. The satisfaction with life scale. J Pers Assess 1 985;49(I):7I-5. https://doi.org//0.1207/s I5327752j pa490I_13.

16: Park AS. The relationship between the parenting stress and psychological well-being of a mother having a child with autism. Korean J Soc Welf 20I2;64(I):225-47. https://doi.org/ 10.1080/20473869.2017.1279843.

17: Werner S, Shulman C. Subjective well-being among family caregivers 
of individuals with developmental disabilities: the role of affiliate stigma and psychosocial moderating variables. Res Dev Disabil 2013;
34(II):4I03-I4. https://doi.org/ 10.1016/j.ridd.2013.08.029.

I8: Nyati Z, Sebit MB. Burden of mental illness on family members, caregivers and the community. East African Med J 2002;79(4):206-9. https://doi.org//0.43 I 4/ eamj.v79i4.8880.

\section{AUTHOR'S CONTRIBUTION}

Following authors have made substantial contributions to the manuscript as under:

SK: Conception and study design, acquisition of data, drafting the manuscript, critical review, approval of final version to be published

IB \& NA: Acquisition of data, analysis and interpretation of data, drafting the manuscript, approval of final version to be published

Authors agree to be accountable for all aspects of the work in ensuring that questions related to the accuracy or integrity of any part of the work are appropriately investigated and resolved.

CONFLICT OF INTEREST
Authors declared no conflict of interest
GRANT SUPPORT AND FINANCIAL DISCLOSURE
Authors have declared no specific grant for this research from any
funding agency in the public, commercial or not-for-profit sectors

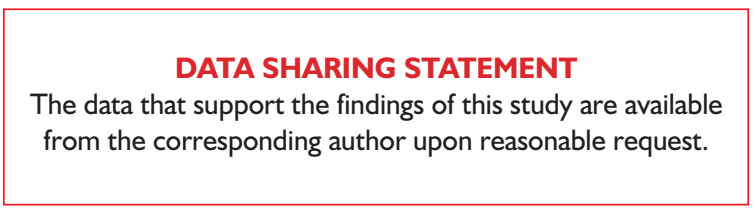

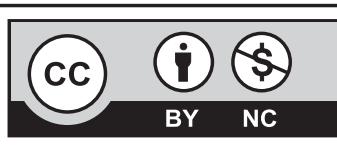

This is an Open Access article distributed under the terms of the Creative Commons Attribution-Non Commercial 2.0 Generic License.

KMUJ web address: www.kmuj.kmu.edu.pk

Email address: kmuj@kmu.edu.pk 